\title{
Organic acids as cloud condensation nuclei: Laboratory studies of highly soluble and insoluble species
}

\author{
P. Pradeep Kumar ${ }^{1,2}$, K. Broekhuizen ${ }^{1}$, and J. P. D. Abbatt ${ }^{1}$ \\ ${ }^{1}$ Department of Chemistry, University of Toronto, Toronto, Ontario, M5S 3H6, Canada \\ ${ }^{2}$ Permanent address: Department of Physics, University of Pune, Pune 411007, India
}

Received: 20 December 2002 - Published in Atmos. Chem. Phys. Discuss.: 4 February 2003

Revised: 23 April 2003 - Accepted: 29 April 2003 - Published: 19 May 2003

\begin{abstract}
The ability of sub-micron-sized organic acid particles to act as cloud condensation nuclei (CCN) has been examined at room temperature using a newly constructed continuous-flow, thermal-gradient diffusion chamber (TGDC). The organic acids studied were: oxalic, malonic, glutaric, oleic and stearic. The $\mathrm{CCN}$ properties of the highly soluble acids - oxalic, malonic and glutaric - match very closely Köhler theory predictions which assume full dissolution of the dry particle and a surface tension of the growing droplet equal to that of water. In particular, for supersaturations between 0.3 and 0.6 , agreement between the dry particle diameter which gives 50\% activation and that calculated from Köhler theory is to within $3 \mathrm{~nm}$ on average. In the course of the experiments, considerable instability of glutaric acid particles was observed as a function of time and there is evidence that they fragment to some degree to smaller particles. Stearic acid and oleic acid, which are both highly insoluble in water, did not activate at supersaturations of $0.6 \%$ with dry diameters up to $140 \mathrm{~nm}$. Finally, to validate the performance of the TGDC, we present results for the activation of ammonium sulfate particles that demonstrate good agreement with Köhler theory if solution non-ideality is considered. Our findings support earlier studies in the literature that showed highly soluble organics to be $\mathrm{CCN}$ active but insoluble species to be largely inactive.
\end{abstract}

\section{Introduction}

Although it has long been known that sub-micron-sized particles act as the nucleation sites for cloud droplets in the atmosphere, there are still considerable uncertainties regarding the chemical composition of the most easily activated cloud condensation nuclei (CCN) and in the detailed manner by

Correspondence to: J. P. D. Abbatt

(jabbatt@chem.utoronto.ca) which activation occurs. For many decades, it has been clear that soluble species in atmospheric particulates play the central role in this regard by lowering the vapour pressure of water over aqueous particles. This vapour pressure lowering effect counteracts the increase in vapour pressure over small droplets that is described by the Kelvin effect. The combination of these two opposing phenomena gives rise to the Köhler equation that describes the supersaturation, $S$, that exists over a solution droplet of radius $r$, assuming equilibrium conditions (Pruppacher and Klett, 1980):

$S=P / P_{\infty}-1=A_{w} \exp \left(\frac{2 \sigma_{\text {solution }} M_{w}}{r \rho_{\text {solution }} R T}\right)-1$

where $P$ is the water vapor pressure of the droplet, $P_{\infty}$ is the vapor pressure over a flat water surface, $A_{w}$ is the water activity in solution, $\sigma_{\text {solution }}$ is the surface tension of the solution, $\rho_{\text {solution }}$ is the density of the solution, $M_{w}$ is the molecular weight of water, and $R$ and $T$ are the ideal gas constant and temperature, respectively. For cloud droplet formation to occur from an aerosol particle, ambient relative humidities must rise above the maximum supersaturation described by the Köhler curve for that particle, and uptake of water vapour by the growing droplet has to be rapid.

Early laboratory studies have demonstrated that the common soluble, inorganic constituents of atmospheric aerosol, such as $\left(\mathrm{NH}_{4}\right)_{2} \mathrm{SO}_{4}$ and $\mathrm{NaCl}$, obey Köhler theory to a reasonable degree (Katz and Kochmond, 1973; Gerber et al., 1977; Cruz and Pandis, 1997). These tests have been performed by exposing particles of a known dry size to a known supersaturation, and then varying the size and/or supersaturation to determine the conditions that give rise to droplet growth. The comparisons between theory and experiment are usually made using the simplest form of Köhler theory where important assumptions are made that the surface tension of the growing droplet is that of water and the droplet solution behaves in an ideal manner. When these assumptions are addressed in detail, the agreement between the observed and

(C) European Geosciences Union 2003 
Table 1. Chemical properties of investigated compounds ${ }^{a}$

\begin{tabular}{|c|c|c|c|c|c|}
\hline Name & Formula & $\begin{array}{c}\text { Molecular } \\
\text { weight } \\
\left(\mathrm{g} \mathrm{mol}^{-1}\right)\end{array}$ & $\begin{array}{c}\text { Density } \\
\left(\mathrm{g} \mathrm{cm}^{-3}\right)\end{array}$ & $\begin{array}{c}\text { Aqueous Solubility } \\
\text { at } 293 \mathrm{~K} \\
\text { (g/100 g of solution) }\end{array}$ & $v$ \\
\hline Ammonium Sulfate & $\left(\mathrm{NH}_{4}\right)_{2} \mathrm{SO}_{4}$ & 132.1 & 1.77 & 43 & 3 \\
\hline Oxalic Acid & $\mathrm{C}_{2} \mathrm{H}_{2} \mathrm{O}_{4}$ & 90.0 & 1.90 & $10.7^{b}$ & $c$ \\
\hline Oxalic Acid & & & & & \\
\hline Dihydrate & $\mathrm{C}_{2} \mathrm{H}_{2} \mathrm{O}_{4} \cdot 2 \mathrm{H}_{2} \mathrm{O}$ & 126.0 & 1.65 & 15.0 & $c$ \\
\hline Malonic Acid & $\mathrm{C}_{3} \mathrm{H}_{4} \mathrm{O}_{4}$ & 104.1 & 1.62 & $62^{b}$ & 1 \\
\hline Glutaric Acid & $\mathrm{C}_{5} \mathrm{H}_{8} \mathrm{O}_{4}$ & 132.1 & 1.42 & $53.7^{b}$ & 1 \\
\hline Oleic Acid & $\mathrm{C}_{18} \mathrm{H}_{34} \mathrm{O}_{2}$ & 282.5 & 0.89 & Very low & 1 \\
\hline Stearic Acid & $\mathrm{C}_{18} \mathrm{H}_{36} \mathrm{O}_{2}$ & 284.5 & 0.94 & Very low & 1 \\
\hline
\end{tabular}

predicted behavior is well within experimental uncertainties (Brechtel and Kreidenweis, 2000). This lends confidence to using Köhler theory as the foundation for our understanding of the activation of droplets from aerosol particles containing soluble inorganic species.

Although inorganic ions comprise a significant component of tropospheric aerosol, it is now known that a comparable fraction of the aerosol mass can consist of an array of water soluble and insoluble organic molecules (e.g. Yu, 2000). These organics can have a wide variation in solubilities, ranging from highly soluble species, such as the small dicarboxylic acids which are formed as a result of photochemical processing, to highly insoluble species, such as long-chain, biogenic fatty acids (Gill et al., 1983). Knowing this, it has been suggested that the organic species may play a significant, yet hitherto poorly quantified, role as $\mathrm{CCN}$ in the atmosphere (Novakov and Penner, 1993). Experimental evidence that organics play an important role as CCN comes from field studies where water soluble organics and the number of CCN are positively correlated, and observations of significant levels of CCN when aerosol sulfate levels are low (Matsumoto et al., 1997; Hegg et al., 1993).

Uncertainties in quantifying the importance of organic $\mathrm{CCN}$ arise in part because it is not known whether the organics act in concert with the inorganic components or whether one class of aerosol, inorganic or organic, dominates over the other in specific environments. Given that recent studies of the composition of single aerosol particles indicate a high degree of internal mixing, i.e. soluble organics and inorganics are commonly detected in the same particle, it is most likely that both species simultaneously contribute to the cloud nucleating ability of tropospheric aerosol (Murphy et al., 1998). Other issues that have not been fully addressed are the relative cloud nucleating roles of biomass-burning generated organic aerosols, freshly emitted particles of biogenic origin, and particles that have undergone a high degree of photo- chemical processing. It is likely that changes in the number of $\mathrm{CCN}$ that prevail in different environments, such as polluted versus clean (e.g. Gilliani et al., 1995), may be due in part to the varying levels and types of organics present in the ambient aerosol.

A few research groups have recently studied the $\mathrm{CCN}$ properties of pure organic species to assess their activity relative to the well-studied inorganics (Cruz and Pandis, 1997; Corrigan and Novakov, 1999; Hudson, 2002). Significant issues to be addressed by laboratory studies of this type include:

1. Do soluble organics obey Köhler theory and thus act in a manner analogous to that displayed by soluble inorganics?

2. What is the role of species of moderate solubility? Does all the dry solute mass contribute to particle activation or only the fraction which is thermodynamically favoured to be in solution (Laaksonen et al., 1998)?

3. Are highly insoluble organics fully $\mathrm{CCN}$ inactive, or can they adsorb/dissolve sufficient amounts of water so as to grow and activate? Alternatively, in a particle of mixed composition, can more water-soluble organics dissolve to some degree in less water-soluble species, so helping to activate the less soluble ones?

4. How rapidly do solid- and liquid-phase organics dissolve in water when exposed to high supersaturations (Hegg et al., 2001; Shantz et al., 2003)? What is the rate of mass transfer of water vapour to a growing organicrich droplet?

5. Do surface-active organic species lower the surface tension and the ambient supersaturation with which the growing droplet is in equilibrium (Shulman et al., 1996; Facchini et al., 1999)? 


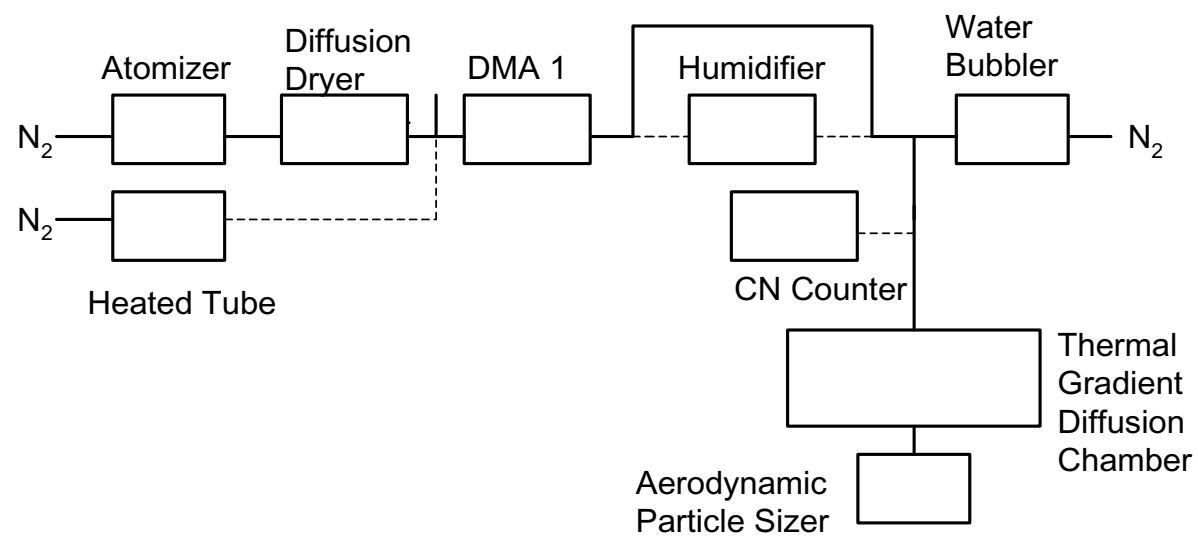

Fig. 1. Schematic diagram of the experimental apparatus. Dashed lines indiate an alternate path that the aerosol flow can take (see text).

In previous studies pure organic particles of known size have been exposed to known supersaturations to determine whether they will activate into cloud droplets or not (Cruz and Pandis, 1997; Corrigan and Novakov, 1999; Hudson, 2002). In these studies, it has been shown that species of very high solubility tend to obey Köhler theory within experimental uncertainties. However, it is intriguing that species of somewhat lower solubility, such as adipic acid, show diverse behavior, sometimes activating in agreement with theory and sometimes activating in a more inhibited manner. Lastly, it has been shown that dioctylphthalate, a highly insoluble but not atmospherically prevalent molecule, is inactive for large particle sizes and high supersaturations (Cruz and Pandis, 1997).

In this work we place particular emphasis on studying sets of molecules of high solubility and of low solubility (see Table 1). In later studies, we will address species of moderate solubility. The specific organic species we have studied here are: three dicarboxylic acids, oxalic $\left(\mathrm{C}_{2} \mathrm{H}_{2} \mathrm{O}_{4}\right)$, malonic $\left(\mathrm{C}_{3} \mathrm{H}_{4} \mathrm{O}_{4}\right)$ and glutaric $\left(\mathrm{C}_{5} \mathrm{H}_{8} \mathrm{O}_{4}\right)$, and two monocarboxylic acids, stearic $\left(\mathrm{C}_{18} \mathrm{H}_{36} \mathrm{O}_{2}\right)$ and oleic $\left(\mathrm{C}_{18} \mathrm{H}_{34} \mathrm{O}_{2}\right)$. The small dicarboxylic acids are highly soluble species formed by photochemical oxidation processes, such as the reaction of ozone with unsaturated hydrocarbons. In particular, they, or their anions, are regularly observed to be some of the most prevalent organic compounds that are identified in tropospheric organic material (Yu, 2000). Stearic and oleic acids were chosen as common biogenic fatty acids that have been detected in tropospheric aerosol (Gill et al., 1983; Stephanou and Stratigakis, 1993). Both are highly surface active, but essentially insoluble in water. Lastly, we present in the paper a detailed description of our continuous-flow, thermal-gradient diffusion chamber (TGDC) which was built in-house. The TGDC is an easily constructed instrument with a novel design that uses commercial particle-counting equipment to determine the number density of activated droplets. Its behaviour has been characterized by detailed studies of the activation of ammonium sulfate particles.

\section{Experimental}

The experimental goals in this work were to measure the activation properties of monodisperse organic particles of a known size under fixed supersaturation conditions. Figure 1 shows a schematic diagram of the experimental system. Particles are generated in one of two methods. For ammonium sulfate, oxalic acid, malonic acid and glutaric acid, the dry solutes were dissolved in $18 \mathrm{MOhm}$ water $(0.3,0.21,0.2$ and $0.3 \mathrm{~g} / \mathrm{L}$, respectively), and then atomized using a commercial atomizer (TSI Inc., Model \#3076) that produces a polydisperse distribution of dilute particles with a mode diameter of $350 \mathrm{~nm}$. In all cases, the particles were then dried to a relative humidity of about $10 \%$ or below by passage through either one or two silica-gel diffusion dryers. The relative humidity was measured using a solid state hygrometer (Fisher Scientific Inc.). Residence time at this relative humidity was about $45 \mathrm{~s}$. For stearic and oleic acids, both of which are highly insoluble in water and so could not be easily atomized from an aqueous solution, the particles were generated by homogeneous nucleation from the gas phase. In particular, a small flow of particle-free, ultra-high-purity nitrogen was passed through a $1-\mathrm{cm}-$ i.d., $10-\mathrm{cm}$-long pyrex tube containing the pure organic. The tube was heated to roughly $105^{\circ} \mathrm{C}$ with heating tape to raise the vapour pressure of the sample. The supersaturation formed when the flow returned to room temperature was sufficient to readily generate large numbers of particles with diameters between 90 and $140 \mathrm{~nm}$.

A monodisperse distribution of the organic particles was formed by passing 0.2 SLM (Standard Liters per Minute) of the polydisperse flow through a differential mobility analyzer (TSI Inc., Model \#3081) referred to in Fig. 1 as DMA 1. The other fraction of the polydisperse flow was discarded at a "T"-junction located just prior to the DMA inlet. Confirmation of the size selected by the DMA was made by performing a tandem experiment using a second DMA (TSI Inc., Model \#3081) coupled to a commercial condensation nucleus counter (TSI Inc., Model \#3025A). For all species 


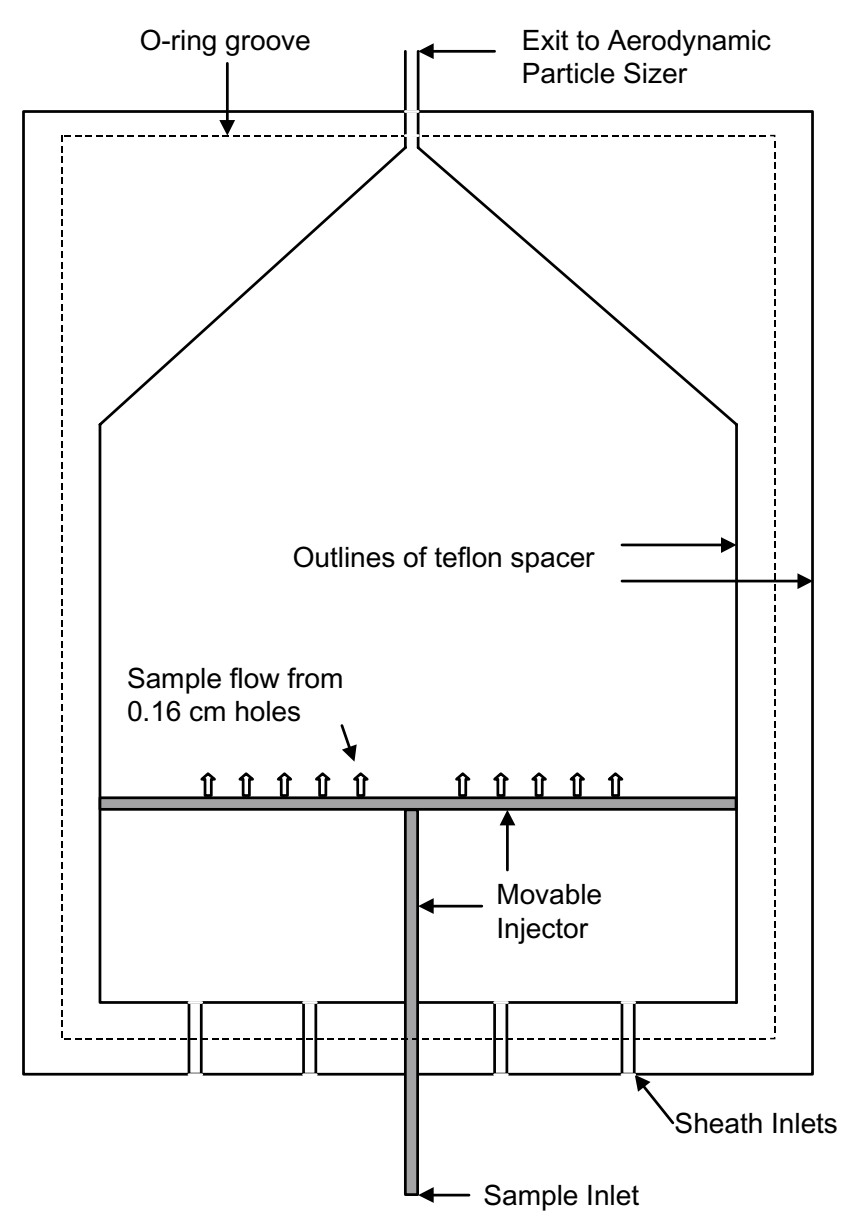

Fig. 2. Horizontal cross-section of the thermal-gradient diffusion chamber.

except glutaric acid, scanning the size setting of the second DMA confirmed that the mode diameters selected by the first DMA were the same as those detected by the second DMA, to within $1.5 \mathrm{~nm}$. The glutaric acid behavior will be described in detail below. We refer to the size of the particles selected by DMA 1 as the "dry particle diameter".

To perform the cloud droplet activation experiments, the monodisperse organic aerosol flow was directed to a homebuilt thermal-gradient diffusion chamber which we describe in detail, given that it is new and has some unique features. Figure 2 shows a cross-sectional view of the unit. The chamber consists of two parallel 0.6-cm-thick copper plates, 25.4$\mathrm{cm}$-wide and 35.6- $\mathrm{cm}$-long, which are mounted horizontally above and below a 1.3-cm-thick Teflon spacer. Heat-transfer fluid from two recirculating baths circulates through $1.3 \mathrm{~m}$ of $0.95-\mathrm{cm}-\mathrm{o}$.d. copper tubing soldered onto the outside surface of each plate. The temperature of each plate is constant during the course of an experiment to better than $\pm 0.01^{\circ} \mathrm{C}$ and the temperature uniformity across the plate is better than $\pm 0.03^{\circ} \mathrm{C}$. This has been established by inserting thermistors (Omega Inc., 44000 Series) into blind holes (0.16-cm-

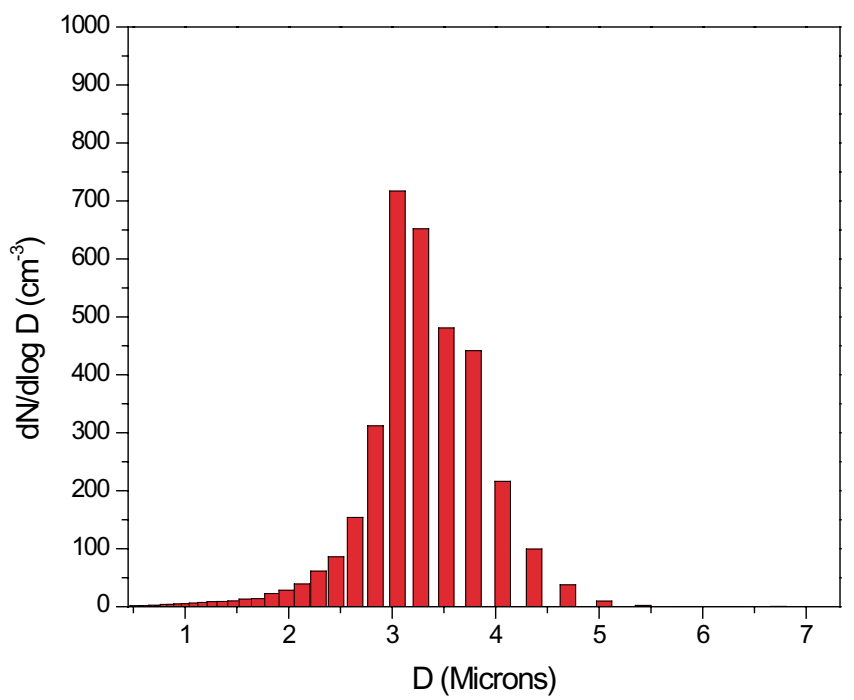

Fig. 3. Sample size distribution of activated droplets measured by the Aerodynamic Particle Sizer for an experiment conducted with ammonium sulfate: Dry Particle Diameter $=140 \mathrm{~nm}, \mathrm{~S}=0.33 \%$, $\mathrm{CN}=150 \mathrm{~cm}^{-3}$.

diameter, 0.48-cm-deep) drilled from the outside, which are located at nine locations across the copper plate surface. Given that the inner surface of the copper plates may have been at a different temperature than the plate itself, we have also mounted thermistors in a number of through holes in the plates. For these, the head of the thermistor projects about $0.5 \mathrm{~mm}$ beyond the face of the inner surface of the plate. The temperatures measured in the blind and through holes agree with each other to $0.03^{\circ} \mathrm{C}$. During the course of an experiment we routinely monitor the temperature of a single thermistor mounted in a through hole in the center of each plate.

Thermal-gradient diffusion chambers operate by maintaining the two plates at slightly different temperatures, creating a linear temperature gradient to develop between them (e.g. Twomey, 1963; Saxena et al., 1970; Hudson, 1989). Their inner surfaces are held at $100 \%$ relative humidity with respect to liquid water at the temperature of the plate. Because the saturation vapour pressure of water varies exponentially with temperature, a supersaturation develops in the center of the flow. To keep the plates wet, we line each surface with moist filter paper at the start of each day of operation. Small amounts of water are added during the day through three holes drilled into the upper plate. The parallel plates are separated by the $1.3-\mathrm{cm}$-thick teflon sheet, the center of which has been machined out. O-rings sitting in grooves on both faces of the teflon sheet insure that a tight seal is made between the teflon spacer and the copper plates. To minimize convective mixing in the chamber, the warmer plate is mounted above the cooler plate. 
Monodisperse aerosol flow enters the chamber through the copper tube injector (shown in Fig. 2) which can slide to different positions along the long dimension of the chamber. In particular, the particle flow passes through a central $0.6-\mathrm{cm}-$ o.d. copper tube to another 0.6-cm-o.d. copper tube soldered at right angles to the first. The aerosol flow exits the injector assembly through ten 0.16 -cm-diameter holes in the second tube which face downstream and inject the flow into the center of the chamber, where the maximum water supersaturation prevails. To confine the aerosol flow to the center of the chamber, a sheath flow of 2 SLM of particle-free nitrogen gas enters the chamber through 4 holes at the upstream end of the chamber, behind the injector. To extend the time that the filter paper stays wet, the sheath flow is humidified to $100 \%$ relative humidity by passing it through a fritted water bubbler immediately prior to entering the chamber. As it passes through the chamber, the sheath flow splits into two by passing either over or under the injector and so helps to confine the particle flow to the center. The entire flow, sheath plus sample, exits through a 0.6-cm-o.d. tube at the downstream end of the chamber and then passes through a short length of tubing to a commercial aerodynamic particle sizing instrument (TSI Inc., Model \#3320) that sizes and counts particles with sizes between 0.5 and 20 microns. For the dimensions of our chamber, the average residence time in the chamber is $20 \mathrm{~s}$ and the Reynolds numbers are roughly 15 , i.e. well in the laminar regime.

An activation experiment is conducted by establishing a steady temperature gradient across the plates that produces a water supersaturation in the center of the chamber of somewhere between 0.3 and $0.9 \%$. The number of condensation nuclei present are then determined by bypassing the TGDC and passing the sample and sheath flows directly to the $\mathrm{CN}$ counter. Typical number densities were between 100 and 300 particles $/ \mathrm{cm}^{3}$. The flows were then directed into the TGDC/APS to measure the number of activated droplets that form for the supersaturation of the experiment. In the absence of particle activation, i.e. either at low supersaturation or small dry particle diameter, the aerodynamic particle sizer detects no particles. However, activated droplets were clearly identified as comprising a narrow particle distribution with a mode diameter of a few microns, as shown for a typical distribution in Fig. 3. For all supersaturations the position of the injector assembly was optimized to yield the most narrow distribution of activated droplets, which always corresponded to the highest fraction of activated droplets. In general, the injector assembly was pulled to the back of the chamber for the lower supersaturations, in order to give enough time for particle growth and activation to occur. For all experiments, the mean temperature of the chamber is maintained roughly $2^{\circ}$ above room temperature so that the activated droplets do not evaporate en route from the TGDC to the APS.

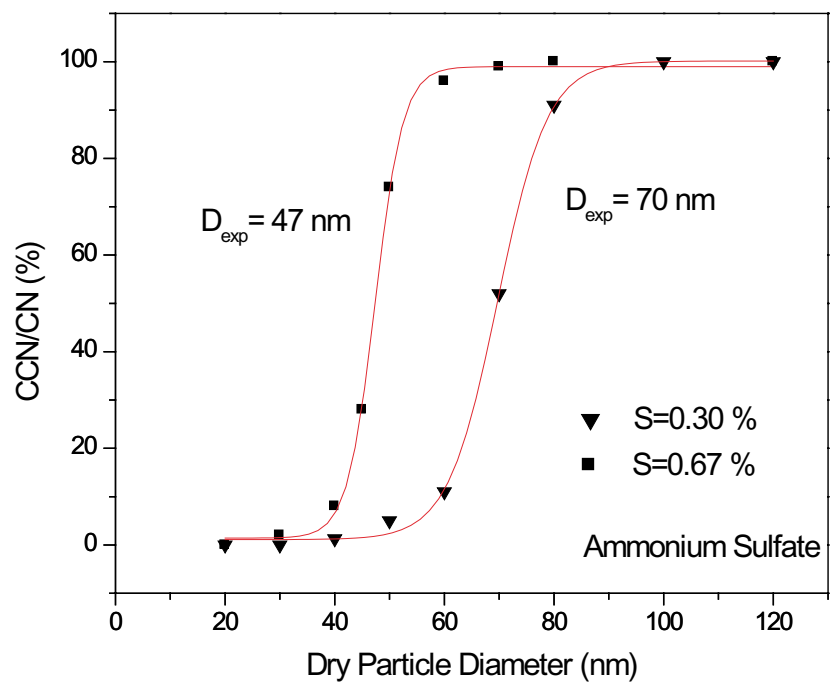

Fig. 4. Ratio of the number of activated droplets ("CCN") relative to the number of condensation nuclei ("CN") plotted as a function of dry particle diameter for ammonium sulfate particles at supersaturations of 0.30 and $0.67 \%$. Vertical axis has been corrected to indicate full activation (see text for explanation).

\section{Results and discussion}

\subsection{Ammonium sulfate and chamber performance}

Ammonium sulfate was chosen as the species to test the performance of our thermal-gradient diffusion chamber because its phase transition behavior as a function of relative humidity is well understood (e.g. Tang et al., 1995, Cziczo and Abbatt, 1997), it has a very high solubility in water, and its $\mathrm{CCN}$-forming behavior has been studied extensively before (Katz and Kochmond, 1973; Gerber et al., 1977; Brechtel and Kreidenweis, 2000).

Given that the efflorescence relative humidity of ammonium sulfate is about $33 \%$ for aerosol particles of the size studied in this work, it is clear that the particles will be solids when they exit the diffusion dryers prior to entering the differential mobility analyzer that performs the size selection. When they enter the TGDC they liquefy as they quickly experience relative humidities above the deliquescence point. Soon after deliquescence they encounter the supersaturation conditions that exist in the center of the chamber and they either activate or not, depending on the maximum supersaturation and the number of moles of solute in the dry particle. In some experiments, the particles passed through a humidifier immediately after DMA 1 and before the TGDC. This consisted of a 6-cm-i.d., 36-cm-long pyrex tube partially filled with liquid water at room temperature that raised the relative humidity to close to $100 \%$. In this configuration, solution droplets entered the TGDC. 
Typical sets of data for the activation of ammonium sulfate particles are shown in Fig. 4 for two supersaturations, 0.30 and $0.67 \%$. On the vertical axis is plotted the ratio of the number of activated droplets relative to the number of condensation nuclei measured in the experiment ("CCN/CN"), where this ratio has been corrected to $100 \%$ activation. For both supersaturations, there is an abrupt transition from no activation at small dry particle sizes to the plateau region indicative of full activation. Although in theory this plateau region should occur at $100 \%$, in practice we routinely observe it to occur at a value between 70 and $80 \%$. This occurred not only in the ammonium sulfate experiments but in the organic acid work as well. Disagreements of this magnitude from the $100 \%$ value are prevalent in the literature for other TGDCs and may arise for a number of reasons (Cruz and Pandis, 1997; Corrigan and Novakov, 1999). First, the aerodynamic particle sizer and the condensation nucleus counter are each specified to determine particle number densities with an accuracy of $\pm 10 \%$. Thus, our measurements lie close to the combined error limits of these two instruments. Second, the fact that our ratio is always below $100 \%$ implies that there may be a loss, or undercounting, of CN in the system (Brechtel and Kreidenweis, 2000). Indeed, we have determined $\mathrm{CN}$ particle losses in the cloud chamber to be on the order of $10 \%$, as measured by comparing the signal from the $\mathrm{CN}$ counter when we bypass the chamber to the signal when we do not. We perform these loss experiments with wet filter paper lining the chamber walls but with no temperature gradient because particle activation would lead to $\mathrm{CN}$ loss. Due to the potential for convective mixing, it is possible that $\mathrm{CN}$ loss rates would be higher when a temperature gradient exists in the chamber. Whatever the source of the disagreement, the flatness of the plateau region at large particle size gives us confidence that full activation is occurring in this region. Correspondingly, we present all of our data in this paper in the manner presented on the vertical axis of Fig. 4, where we have scaled all of our experimental CCN/CN ratios by the reciprocal of the maximum activation fraction observed for large dry particle diameters. The reproducibility of each data point is better than $\pm 5 \%$.

We refer to the dry particle size which gives rise to $50 \%$ activation as the "experimental activation diameter, $\mathrm{D}_{\exp }$ ". It is determined by fitting a sigmoidal function to data plotted in the manner of Fig. 4. The values of $D_{\exp }$ for ammonium sulfate are listed in Table 2 and are plotted in Fig. 5 as a function of the theoretical activation diameter, $D_{\text {Köhler Standard, }}$ calculated from standard Köhler theory. The scatter in Fig. 5 gives a measure of the reproducibility of the experiment, which is on the order of $\pm 3 \mathrm{~nm}$. We note that there was no dependence of the values of $D_{\exp }$ on whether we used the humidifier to induce deliquescence of the particles before entering the TGDC or not, consistent with our belief that the dry particles readily deliquesce upon entering the chamber. Also, particle number densities were varied between 100 and $500 \mathrm{~cm}^{-3}$ and, again, there was no effect on the observed behavior. At
Table 2. Experimental and theoretical activation diameters for ammonium sulfate

\begin{tabular}{|c|c|c|c|}
\hline $\begin{array}{c}\text { Supersaturation } \\
(\%)\end{array}$ & $\begin{array}{l}D_{\exp } \\
(\mathrm{nm})\end{array}$ & $\begin{array}{c}\text { D Köhler Standard }_{(\mathrm{nm})} \\
\end{array}$ & $\begin{array}{c}\text { D }_{\text {Köhler New }} \\
(\mathrm{nm})\end{array}$ \\
\hline 0.89 & 36 & 28.8 & 31.9 \\
\hline 0.89 & 35 & 28.8 & 31.9 \\
\hline 0.86 & 39 & 29.4 & 32.7 \\
\hline 0.76 & 44 & 32.0 & 35.1 \\
\hline 0.67 & 47 & 34.8 & 37.6 \\
\hline 0.48 & 57 & 43.4 & 46.5 \\
\hline 0.48 & 53 & 43.4 & 46.5 \\
\hline 0.47 & 52 & 44.0 & 47.2 \\
\hline 0.44 & 53 & 46.0 & 49.3 \\
\hline 0.40 & 59 & 49.0 & 52.6 \\
\hline 0.37 & 66 & 51.7 & 55.4 \\
\hline 0.36 & 59 & 52.6 & 56.4 \\
\hline 0.36 & 60 & 52.6 & 56.4 \\
\hline 0.34 & 67 & 54.7 & 58.5 \\
\hline 0.31 & 68 & 58.0 & 62.0 \\
\hline 0.30 & 67 & 59.4 & 63.2 \\
\hline 0.29 & 70 & 60.8 & 64.4 \\
\hline
\end{tabular}

significantly higher number densities, there is the possibility that the local supersaturation will be lowered by the transfer of water vapour from the gas phase to the particles.

To calculate DKöhler Standard we have used Eq. (1), where the activity of the solution $\left(A_{w}\right)$ is described by Eqs. (2) and (3), which express Raoult's law and assume ideal solution behavior (Pruppacher and Klett, 1980):

$A_{w}=1-B / r^{3}$

and

$B=\left(3 v m_{s} M_{w}\right) /\left(4 \pi \rho_{\text {solution }} M_{s}\right)$,

where $v$ is the van't Hoff factor expressing the number of ions or molecules formed from the dissolution of one molecule of solute, $m_{s}$ is the mass of the solute in the dry particle, and $M_{S}$ is the molecular weight of the solute. In particular, by identifying the local maximum in the Köhler supersaturation curve it can be readily shown that the critical supersaturation $\left(S_{c}\right)$ required for activation can be expressed as:

$S_{c}=\left(4 A^{3} / 27 B\right)^{1 / 2}$,

where $A$ can be readily calculated:

$A=\left(2 \sigma_{\text {solution }} M_{w}\right) /\left(\rho_{\text {solution }} R T\right)$.

By setting $S_{c}$ to the experimental value in the TGDC, the value of $B$ can be determined from Eq. (4) and, hence, the mass of solute in the dry particle $\left(m_{s}\right)$ from Eq. (3). Assuming particle sphericity, the diameter of the dry particle which 


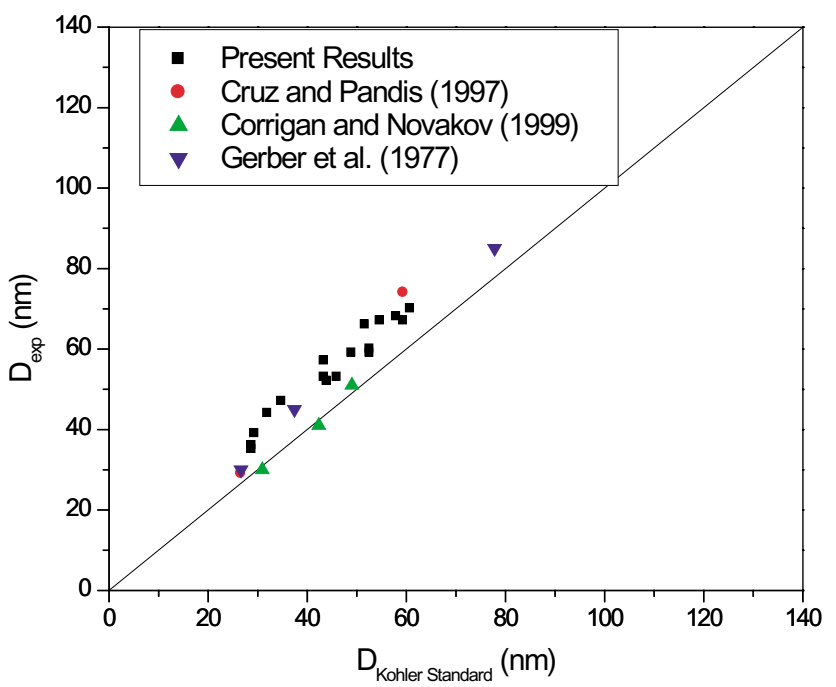

Fig. 5. For ammonium sulfate, comparison between the experimental values of the dry particle diameter that give $50 \%$ activation $\left(D_{\text {exp }}\right)$ and the theoretical predictions of this quantity from standard Köhler theory ( $\mathrm{D}_{\text {Köhler Standard }}$ ) described by Eqs. (1), (2) and (3). Each point represents an experiment of the type shown in Fig. 4 conducted at a fixed superaturation between 0.29 and $0.89 \%$. Also included are results from the literature.

gives rise to this critical supersaturation can then be calculated:

$\mathrm{D}_{\text {Köhler }}=2\left(3 m_{s} / 4 \pi \rho_{s}\right)^{1 / 3}$,

where $\rho_{S}$ is the density of the pure solute particle. The specific values for the parameters used in the calculations are: $T=298.15 \mathrm{~K}, \rho_{\text {solution }}=\rho_{\text {water }}=997 \mathrm{~kg} / \mathrm{m}^{3}, \sigma_{\text {solution }}=$ $\sigma_{\text {water }}=0.07197 \mathrm{~J} / \mathrm{m}^{2}, \quad \rho_{\left(\mathrm{NH}_{4}\right)_{2} \mathrm{SO}_{4}}=1769 \mathrm{~kg} / \mathrm{m}^{3}$, $M_{\left(\mathrm{NH}_{4}\right)_{2} \mathrm{SO}_{4}}=0.1321 \mathrm{~kg} / \mathrm{mole}, M_{w}=0.01802 \mathrm{~kg} / \mathrm{mole}$, and $v=3$ (Lide, 2002).

In Fig. 5, we also include measurements from other workers who performed experiments in this manner, i.e. measurements of $\mathrm{D}_{\text {exp }}$ at a fixed $S$, for ammonium sulfate. The figure illustrates that the experimental measurements performed in this study are in line with those performed by other research groups using similar aerosol preparation methods but different TGDC's (Gerber et al., 1977; Cruz and Pandis, 1997; Corrigan and Novakov, 1999). However, we note that there appears to be a systematic discrepancy between the calculated and observed dry diameters, on the order $10 \mathrm{~nm}$ or so, with the observed dry diameters being somewhat larger than those theoretically predicted. Cruz and Pandis (1997) have summarized many of the possible sources of error in experiments of this type. They include relatively small errors that might arise in the assumption of dry particle sphericity when selected by DMA 1 , calibration errors in DMA 1 itself, multiple charging effects in the DMA and inaccuracies in the calculated supersaturation that can result from uncertainties in the plate temperatures. In this paper, we point out that a siz-

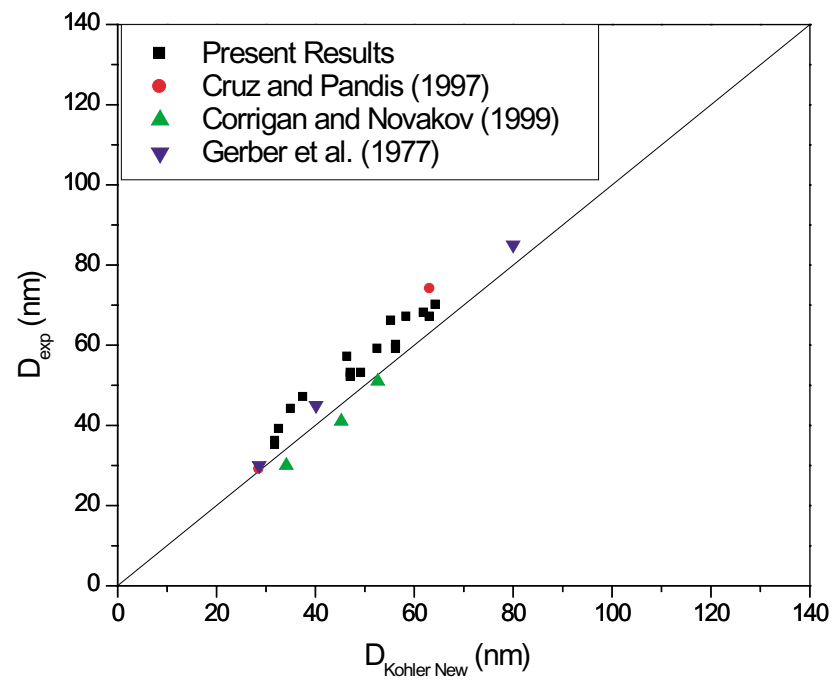

Fig. 6. Same plot as Fig. 5 except that the water activity in the Köhler prediction $\left(\mathrm{D}_{\text {Köhler New }}\right.$ ) has been taken from Clegg et al. (1996).

able component of the discrepancy can be accounted for by the assumption that the solutions behave in an ideal manner (Pruppacher and Klett, 1980). In particular, we have recalculated the theoretical dry diameters using a Pitzer activitycoefficient, thermodynamic model which relates water activity in aqueous salt solutions to the molality of the solution (Clegg et al., 1996). For ammonium sulfate, the Clegg et al. (1996) model is tightly constrained by bulk experimental measurements. With these new water activities, Eq. (1) was used to determine, by trial and error, the dry particle diameter for the critical supersaturation of the experiment. As shown in Fig. 6, when we compare the experimental measurements to theoretical values with more accurate water activities, the level of the disagreement between theory and experiment is reduced by about a factor of two.

The potential importance of using true solution activities has been pointed out by a number of other workers (Konopka, 1996; Chylek and Wong, 1998). In the past, it has been common practice to use an "effective" van't Hoff factor in Köhler theory calculations for ammonium sulfate, which had a value of between 2 and 2.5, in order to force agreement between measured and calculated diameters and thus take into account solution non-ideality (e.g. Gerber et al., 1977; Rogers and Yau, 1989). It is important to note that this does not imply at a physical level that ammonium sulfate does not fully dissociate in solution. Given the high solubility of ammonium sulfate and the dilute nature of the growing solution droplets, full dissociation is expected.

For all of our experiments, the onset of activation does not occur in a fully stepwise manner. Instead, for low supersaturations of close to $0.3 \%$, the transition from about 20 to $80 \%$ activation occurs for ammonium sulfate over a range of dry particle diameters of about $13 \mathrm{~nm}$. A sizable component of 


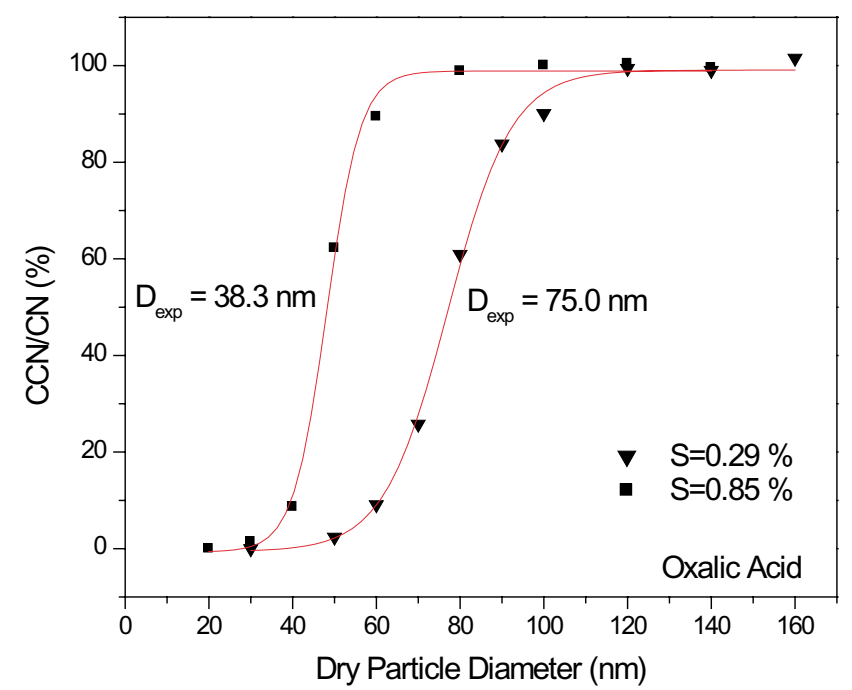

Fig. 7. Ratio of the number of activated droplets ("CCN") relative to the number of condensation nuclei ("CN") plotted as a function of dry particle diameter for oxalic acid dihydrate particles at supersaturations of 0.29 and $0.85 \%$. Vertical axis has been corrected to indicate full activation (see text for explanation).

this breadth arises from the fact that the particle size distribution produced by DMA 1 is not fully monodisperse. For example, for particle sizes of close to $65 \mathrm{~nm}$, the cumulative size distribution of the sized particles changes from values of 20 to $80 \%$ over a range of about $6 \mathrm{~nm}$. We believe that the other reason for the spread of dry particle diameters arises from the fact that particles may not all experience the maximum supersaturation present in the chamber, e.g. some particles are not injected precisely into the center. Indeed, when we first evaluated the performance of the chamber with a sample to sheath flow ratio much larger than the one used for the results reported here, the activation occurred more gradually as a function of dry particle diameter. We note that the breadth of this transition is either comparable to or somewhat tighter than those presented by the other reports in the literature that present characteristics of TGDCs of this nature (Cruz and Pandis, 1997; Corrigan and Novakov, 1999).

We believe the experiments described above validate the performance of our new TGDC. In particular, the close agreement between the theoretical and observed dry diameters indicates that we accurately know the maximum supersaturation in the chamber. The tightness of the activation as a function of dry particle diameter indicates that only a narrow range of supersaturations is sampled and the lack of dependence of the activation on the particle number density indicate that the maximum supersaturation is not suppressed by the activation process itself.

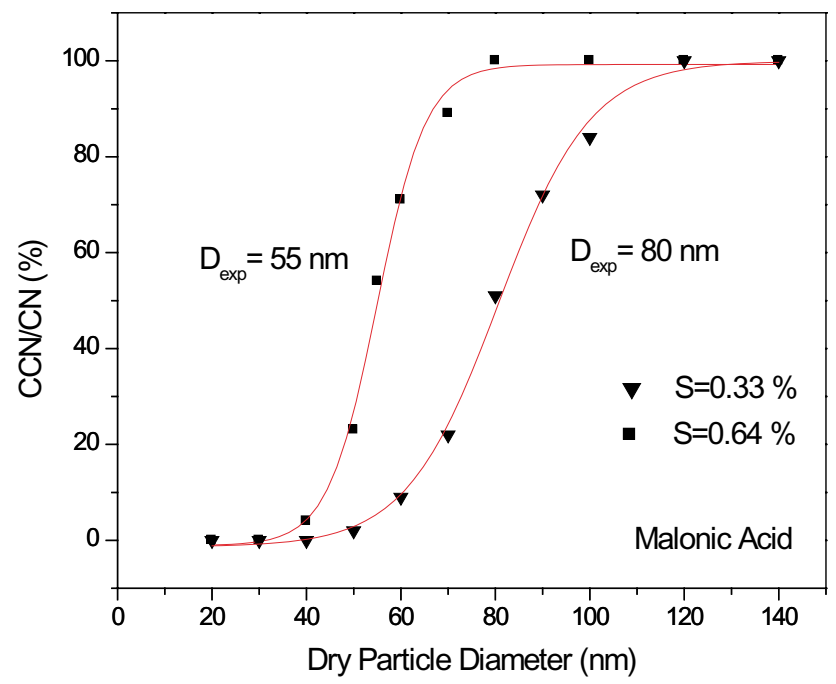

Fig. 8. Ratio of the number of activated droplets ("CCN") relative to the number of condensation nuclei ("CN") plotted as a function of dry particle diameter for malonic acid particles at supersaturations of 0.33 and $0.64 \%$. Vertical axis has been corrected to indicate full activation (see text for explanation).

\subsection{Oxalic and malonic acid}

Experimental results for oxalic and malonic acid are presented in Figs. 7 and 8 (and Table 3). Qualitatively, the forms of the curves are the same as those for ammonium sulfate indicating that these organic acids activate in a similar manner. In Fig. 9 and Table 3 a comparison is made between experimental results and Köhler theory predications assuming ideal solutions. Note that we include theoretical predictions assuming that oxalic acid droplets crystallize to form either anhydrous oxalic acid or the dihydrate of oxalic acid. In an additional project in our laboratory (Braban and Abbatt, 2003) we have shown using aerosol infrared spectroscopy that after efflorescence, micron-sized oxalic acid aqueous droplets can exist in either the anhydrous or hydrate form. In particular, at low relative humidities the anhydrous form is stable whereas at relative humidities above about $15 \%$, the dihydrate is stable. The close agreement between the results and the predictions for the dihydrate lead us to believe that the dihydrate is prevalent in our experiment and is size-selected by the first DMA. Note also that for these calculations, the van't Hoff factor was chosen to be unity for malonic (and glutaric acid) because the pKa for the dissociation of the first proton from malonic acid is sufficiently high, 2.33 (Lide, 2002), that no more than $10 \%$ of the dissolved solute will dissociate in droplets of the size close to the critical activation diameter. This is not the case for oxalic acid, which has a first pKa of 1.23 (Lide, 2002). And so, for each point of the Köhler calculations, the droplet concentration of oxalic acid was calculated and used along with the acid dissociation constant to determine the percent dissociation of the 
Table 3. Experimental and theoretical activation diameters for organic acids

\begin{tabular}{cccc}
\hline Organic Acid & Supersaturation $(\%)$ & $D_{\exp }(\mathrm{nm})$ & $D_{\text {Köhler Standard }}(\mathrm{nm})$ \\
\hline Oxalic & 0.29 & 77 & $75.0 / 64.0^{a}$ \\
& 0.40 & 65 & $61.3 / 52.3^{a}$ \\
& 0.60 & 48 & $47.4 / 40.6^{a}$ \\
Malonic & 0.85 & 41 & $38.3 / 32.6^{a}$ \\
& 0.55 & 57 & 54.3 \\
& 0.64 & 55 & 49.1 \\
& 0.63 & 56 & 49.6 \\
Glutaric & 0.33 & 80 & 76.3 \\
& 0.35 & 76 & 73.4 \\
& 0.46 & 71 & 69.4 \\
\hline
\end{tabular}

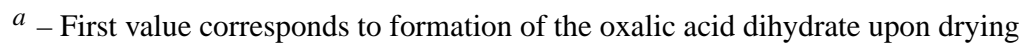
and the second value to the formation of anhydrous oxalic acid.

acid. The van't Hoff factor was then modified according to this calculated percent dissociation. For example, the oxalic acid in a $0.1 \mathrm{M}$ droplet would be $53 \%$ dissociated, leading to a van't Hoff factor of 1.53 rather than 1 .

The close agreement between the experimental results and the predictions assuming full solubility support previous findings that small di-acids are fully active and obey standard Köhler theory (Cruz and Pandis, 1997). The fact that the organic acid experimental results match theory assuming Raoult's law behavior better than do the ammonium sulfate results is probably an indication that an ionic solution is more likely to exhibit non-ideality than a neutral one.

\subsection{Glutaric acid}

For glutaric acid, somewhat erratic and unexpected activation behavior was observed in experiments performed in the mode employed for the other studies reported in this paper. In particular, activation occurred over a much wider range of dry particle diameters than was exhibited with other molecules and the experimental activation diameters were considerably larger than those predicted by Köhler theory. This was unexpected based on the very high solubility of glutaric acid.

An indication of the underlying source of this behavior came from tandem DMA experiments which sought to determine if the particle size selected by DMA 1 was confirmed by DMA 2. For all other species the agreement between the two sizes was excellent, to within a couple of nanometers. However, for glutaric acid a broad range of particle sizes was observed by DMA 2. This broad distribution extended from the size selected by DMA 1 to a peak at a somewhat smaller size. We infer from this that the glutaric acid particles were not stable, and that in the time between the two DMAs they were either fissioning or restructuring to a smaller size. The observed activation behavior was consistent with this hypothesis if the same size change were occurring prior to entering

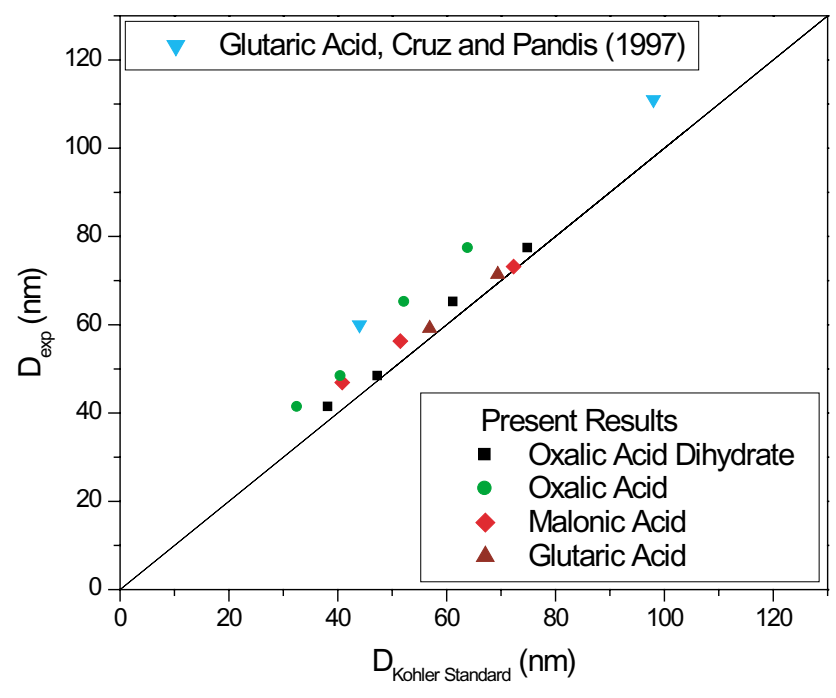

Fig. 9. For all organic acids studied in this work, comparison between the experimental values of the dry particle diameter that give $50 \%$ activation $\left(\mathrm{D}_{\mathrm{exp}}\right)$ and the theoretical predications of this quantity from standard Köhler theory ( $\mathrm{D}_{\text {Köhler Standard }}$ ) described by Eqs. (1), (2) and (3). Each point represents an experiment conducted at a fixed superaturation between 0.29 and $0.85 \%$. Also included are results from the literature. For oxalic acid, two sets of points are included assuming formation of anhydrous oxalic acid and oxalic acid dihydrate, respectively.

the TGDC. We do not have a good physical rationale for why the glutaric acid particles behaved in this manner.

Despite drying the particles to varying degrees and giving them longer residence times before entering the first DMA, this behavior persisted and so we performed the glutaric acid activation experiments in a novel manner. In particular, we used a tandem DMA aerosol source with the two DMAs selecting the same particle size. In addition, by adding a 


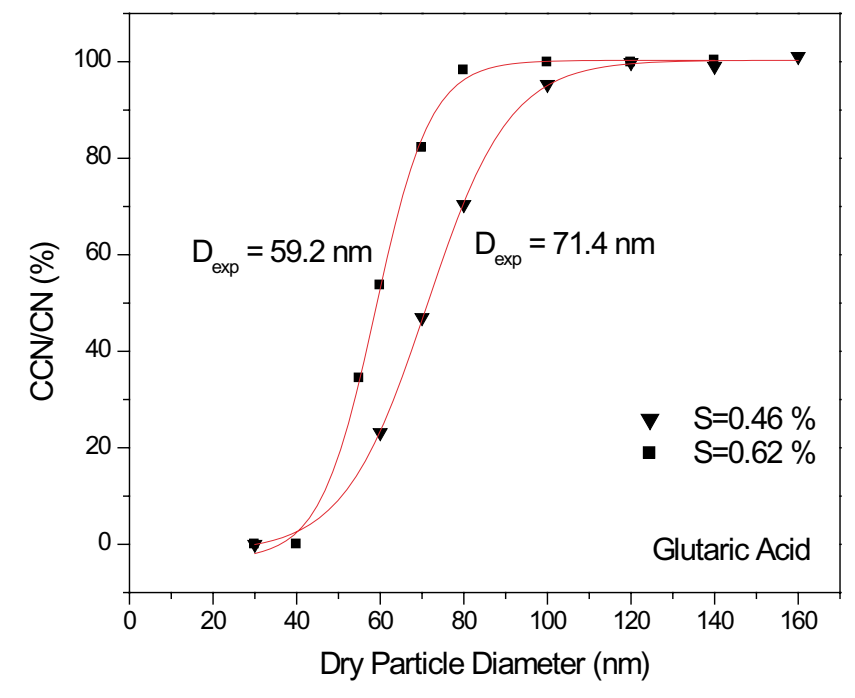

Fig. 10. Ratio of the number of activated droplets ("CCN") relative to the number of condensation nuclei ("CN") plotted as a function of dry particle diameter for glutaric acid particles at supersaturations of 0.46 and $0.62 \%$. Vertical axis has been corrected to indicate full activation (see text for explanation).

large pyrex tube to the line we greatly increased the residence time between the two DMAs. In this configuration, we believe that only particles that have considerable stability pass through both DMAs and we have some confidence in the particle sizes coming from the second DMA.

In this mode of operation, the activation plot has the same form as that observed for the other species, with a steep transition from non-activating particles to those that activate (see Fig. 10). In addition, as shown in Fig. 9 and in Table 3, the observed activation diameters are in very good agreement with the Köhler theory predictions.

Other workers who have studied glutaric acid have not reported the unusual "size change" behavior of the type we observed. In CCN experiments, Cruz and Pandis (1997) report that it activates within $13 \mathrm{~nm}$ of the theoretical values for supersaturations of 0.3 and $1.0 \%$. However, it is noteworthy that Hudson (2002) reported that $200 \mathrm{~nm}$ glutaric acid particles activated well in CCN experiments but that $20 \mathrm{~nm}$ particles did not. Other surprising behavior reported for glutaric acid comes from Peng et al. (2001) who noted that deliquescence phase transitions occurred over a much longer timescale than with other molecules.

\subsection{Stearic and oleic acids}

The final class of molecules studied were two long-chain fatty acids, stearic and oleic acids, both of which are essentially insoluble in water. For both species, we observed no activation $(\mathrm{CCN} / \mathrm{CN}<0.5 \%)$ for particle diameters up to $140 \mathrm{~nm}$ and supersaturations of 0.6 and below. By contrast, assuming full dissolution Köhler theory predicts that dry particle diameters of 86 and $87 \mathrm{~nm}$ for stearic acid and oleic acid, respectively, would activate at supersaturations of $0.6 \%$. These results are in accord with a report of another insoluble species, dioctylphthalate, which has also shown to be inactive under similar conditions (Cruz and Pandis, 1997). Similarly, Hudson (2002) has shown that stearic acid does not readily activate. These results are not surprising given the low water solubility of these fatty acids.

\section{Summary and atmospheric implications}

In this paper we have described the design and performance of a new continuous-flow thermal-gradient diffusion chamber. The chamber is easily constructed and the accompanying particle counting equipment is commercially available and well-tested; hence we believe this TGDC design may be adopted by other laboratories interested in studies of this type. To evaluate the performance of the chamber we have demonstrated that dry ammonium sulfate particles activate within $10 \mathrm{~nm}$ of the dry diameter predicted by standard Köhler theory, where assumptions are made that the solution is ideal and has the surface tension of pure water. When the activity of the solution is calculated using a state-of-the-art thermodynamic model (Clegg et al., 1996), the agreement between the experimental and predicted results is improved by about a factor of two. In general, the chamber operates at a level comparable to others described in the literature, both in the accuracy with which we establish known maximum supersaturations in the chamber, and the narrow range of supersaturations sampled by particles in the flow. Because we can control the time the particles are exposed to the maximum supersaturation by adjusting the position of the particle injector, we have the capability in later studies to study the kinetics of particle growth and activation.

A suite of organic acids, including oxalic, malonic, glutaric, stearic and oleic, has been studied using the TGDC. It was found that except for oleic acid and stearic acid, all closely obey the predictions of standard Köhler theory assuming full dissolution and a surface tension for the droplet equal to that of water. These are not surprising observations given the high solubility of these small acids. We note that these observations are in general support of those already in the literature (Cruz and Pandis, 1997; Corrigan and Novakov, 1999; Hudson, 2002). On the other hand, highly insoluble species such as stearic and oleic acid do not activate at high supersaturation and large particle diameters.

From a predictive perspective, it is important to point out that standard Köhler theory, where it is assumed that the dry particles are fully soluble and the droplets have the surface tension of water, does an excellent job of predicting activation, even for pure particles consisting of slightly surface active molecules. Also, it is interesting that all the organics adhere to standard Köhler theory, assuming solution ideality, somewhat better than does ammonium sulfate. This is 
likely because non-ideality is strongly affected by solution ionic strength.

From the perspective of the atmosphere, it is clear that highly soluble organics will be fully active in cloud activation whereas particles composed of insoluble species, such as oleic and stearic acid, will not. In a future publication we will examine the degree to which species of moderate solubility activate. In addition, knowing that ambient atmospheric aerosols contain small amounts of large numbers of different organic species another future goal in this project is to determine the extent to which mixtures of organics and inorganics obey Köhler theory, and the effect which gas-aerosol heterogeneous chemistry has on the $\mathrm{CCN}$ properties of organic aerosols.

Acknowledgement. This work has been funded by grants from the Canadian Foundation for Climate and Atmospheric Sciences (CFCAS), Natural Sciences and Engineering Research Council (NSERC), Canada Foundation for Innovation (CFI) and Ontario Innovation Trust (OIT). The authors acknowledge helpful communications with S. Clegg, J. Hallett and R. Leaitch.

\section{References}

Braban, C. F., Carroll, M. A., Styler, S. A., and Abbatt, J. P. D.: Phase transitions of malonic and oxalic acid aerosols, J. Phys. Chem. A., submitted, 2003.

Brechtel, F. J. and Kreidenweis, S. M.: Predicting particle critical supersaturation from hygroscopic growth measurements in the humidified TDMA. Part I: Theory and sensitivity studies, J. Atmos. Sci., 57, 1854-1871, 2000.

Chylek, P. and Wong, J. G. D.: Erroneous use of the modified Köhler equation in cloud and aerosol physics applications, J. Atmos. Sci., 55, 1473-1477, 1998.

Clegg, S. L., Milioto, S., and Palmer, D. A.: Osmotic and activity coefficients of aqueous $\left(\mathrm{NH}_{4}\right)_{2} \mathrm{SO}_{4}$ as a function of temperature, and aqueous $\left(\mathrm{NH}_{4}\right)_{2} \mathrm{SO}_{4}-\mathrm{H}_{2} \mathrm{SO}_{4}$ mixtures at $298.15 \mathrm{~K}$ and 323.15 K, J. Chem. Eng. Data, 41, 455-467, 1996.

Corrigan, C. E. and Novakov, T.: Cloud condensation nucleus activity of organic compounds: a laboratory study, Atmos. Environ., 33, 2661-2668, 1999.

Cruz, C. N. and Pandis, S. N.: A study of the ability of pure secondary organic aerosol to act as cloud condensation nuclei, Atmos. Environ., 31, 2205-2214, 1997.

Cziczo, D. J., Nowak, J. B., Hu, J. H., and Abbatt, J. P. D.: Infrared spectroscopy of model tropospheric aerosols as a function of relative humidity: Observation of deliquescence and crystallization, J. Geophys. Res., 102, 18 843-18 850, 1997.

Facchini, M. C., Mircea, M., Fuzzi, S., and Charlson, R. J.: Cloud albedo enhancement by surface-active organic solutes in growing droplets, Nature, 401, 257-259, 1999.

Gerber, H. E., Hoppel, W. A., and Wojciechowski, T. A.: Experimental verification of the theoretical relationship between size and critical supersaturation of salt nuclei, J. Atmos. Sci., 34, 1836-1841, 1977.

Gilliani, N. V., Schwartz, S. E., Leaitch, W. R., Strapp, J. W., and Isaac, G. A.: Field observations in continental stratiform clouds Partitioning of cloud particles between droplets and unactivated interstitial aerosols, J. Geophys. Res., 100, 18 687-18 706, 1995.
Gill, P. S., Graedel, T. E., and Weschler, C. J.: Organic films on atmospheric aerosol particles, fog droplets, cloud droplets, raindrops, and snowflakes, Rev. Geophys. Space Phys., 21, 903-920, 1983.

Hegg, D. A., Ferek, R. J., and Hobbs, P. V.: Light scattering and cloud condensation nucleus activity of sulfate aerosol measured over the northeast Atlantic ocean, J. Geophys. Res., 98, 14887 $14894,1993$.

Hegg, D. A., Gao, S., Hoppel, W., Frick, G., Caffrey, P., Leaitch, W. R., Shantz, N., Ambrusko, J., and Albrechcinski, T.: Laboratory studies of the efficiency of selected organic aerosols as $\mathrm{CCN}$, Atmos. Res., 58, 155-166, 2001.

Hudson, J. G.: An instantaneous CCN spectrometer, J. Atmos. Ocean. Tech., 6, 1055-1065, 1989.

Hudson, J. G.: Laboratory CCN measurements of organic substances, Abstract Number 10.6, 11th Conference on Cloud Physics, American Meteorological Society, Ogden, USA, 2002.

Katz, U. and Kocmond, W. C.: An investigation of the sizesupersaturation relationship of soluble condensation nuclei, J. Atmos. Sci., 30, 160-165, 1973.

Konopka, P.: A reexamination of the derivation of the equilibrium supersaturation curve for soluble particles, J. Atmos. Sci., 53, 3157-3163, 1996.

Laaksonen, A., Korhonen, P., Kulmala, M., and Charlson, R. J.: Modification of the Köhler equation to include soluble trace gases and slightly soluble substances, J. Atmos. Sci., 55, 853862, 1998.

Lide, D. R. (Ed.): CRC Handbook of Chemistry and Physics, CRC Press, 3rd Electronic Edition, Knovel Scientific and Engineering Databases (http://www.knovel.com/knovel2/), 2002.

Matsumoto, K., Tanaka, H., Nagao, I., and Ishizaka, Y.: Contribution of particulate sulfate and organic carbon to cloud condensation nuclei in the marine atmosphere, Geophys. Res. Lett., 24 , 655-658, 1997.

Murphy, D. M., Thomson, D. S., and Mahoney, M. J.: In-situ measurements of organics, meteoritic material, mercury and other elements in aerosols at 5 and $19 \mathrm{~km}$, Science, 282, 1664-1669, 1998.

Novakov, T. and Penner, J. E.: Large contribution of organic aerosols to cloud-condensation nuclei concentrations, Nature, 365, 823-826, 1993.

Peng, C., Chan, M. N., and Chan, C. K.: The hygroscopic properties of dicarboxylic and multifunctional acids: Measurements and UNIFAC predictions, Environ. Sci. Technol., 35, 4495-4501, 2001.

Pruppacher, H. R. and Klett, J. D.: Microphysics of clouds and precipitation, D. Reidel Publishing, Boston, 1980.

Rogers, R. R. and Yau, M. K.: A short course in cloud physics, 3rd Ed., Pergamon Press, Oxford, 1989.

Saxena, V. K., Burford, J. N., and Kassner, J. L.: Operation of a thermal diffusion chamber for measurements on cloud condensation nuclei, J. Atmos. Sci., 27, 73-80, 1970.

Saxena, P. and Hildemann, L. M.: Water-soluble organics in atmospheric particles: A critical review of the literature and application of thermodynamics to identify candidate compounds, J. Atmos. Chem., 24, 57-109, 1996.

Shantz, N. C., Leaitch, W. R., and Caffrey, P.: The effect of organics of low solubility on the growth rate of cloud droplets, J. Geophys. Res. - Atmospheres, accepted, 2003. 
Shulman, M. L., Jacobson, M. C., Carlson, R. J., Synovec, R. E., and Young, T. E.: Dissolution behavior and surface tension effects of organic compounds in nucleating cloud droplets, Geophys. Res. Lett., 23, 277-280, 1996.

Stephanou, E. G. and Stratigakis, N.: Oxocarboxylic and $\alpha, \omega-$ dicarboxylic acids: Photooxidation products of biogenic unsaturated fatty acids present in urban aerosols, Environ. Sci. Technol., 27, 1403-1407, 1993.
Tang, I. N., Fung, K. H., Imre, D. G., and Munkelwitz, H. R.: Phase transformation and metastability of hygroscopic microparticles, Aerosol Sci. Technol., 23, 443-453, 1995.

Twomey, S.: Measurements of natural cloud nuclei, J. Rech. Atmos., 1, 101-105, 1963.

Yu, S.: Role of organic acids (formic, acetic, pyruvic and oxalic) in the formation of cloud condensation nuclei $(\mathrm{CCN})$ : A review, Atmos. Res., 53, 185-217, 2000. 